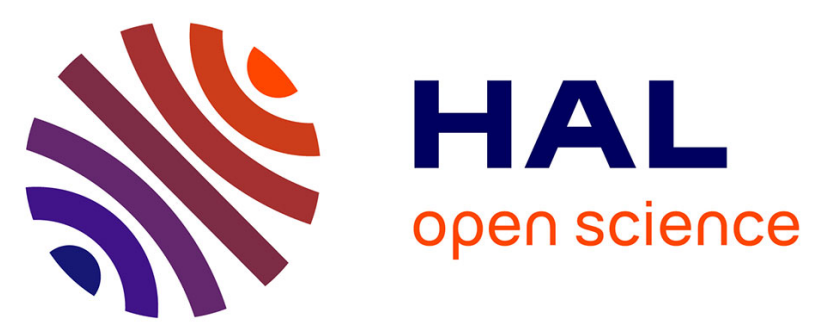

\title{
From physical inactivity to immobilization: Dissecting the role of oxidative stress in skeletal muscle insulin resistance and atrophy
}

Nicolas Pierre, Zéphyra Appriou, Arlette Gratas-Delamarche, Frédéric Derbré

\section{- To cite this version:}

Nicolas Pierre, Zéphyra Appriou, Arlette Gratas-Delamarche, Frédéric Derbré. From physical inactivity to immobilization: Dissecting the role of oxidative stress in skeletal muscle insulin resistance and atrophy. Free Radical Biology and Medicine, 2016, 98, pp.197-207. 10.1016/j.freeradbiomed.2015.12.028 . hal-01255823

HAL Id: hal-01255823

https://hal-univ-rennes1.archives-ouvertes.fr/hal-01255823

Submitted on 27 Jan 2016

HAL is a multi-disciplinary open access archive for the deposit and dissemination of scientific research documents, whether they are published or not. The documents may come from teaching and research institutions in France or abroad, or from public or private research centers.
L'archive ouverte pluridisciplinaire HAL, est destinée au dépôt et à la diffusion de documents scientifiques de niveau recherche, publiés ou non, émanant des établissements d'enseignement et de recherche français ou étrangers, des laboratoires publics ou privés. 


\title{
ACCEPTED MANUSCRIPT
}

From physical inactivity to immobilization: dissecting the role of oxidative stress in skeletal muscle insulin resistance and atrophy

Nicolas Pierre ${ }^{1}$, Zephyra Appriou ${ }^{1}$, Arlette Gratas-Delamarche ${ }^{1}$, Frédéric Derbré $^{1^{*}}$

${ }^{1}$ EA1274 Laboratory "Movement, Sport and health Sciences" M2S, Rennes 2 University ENS Rennes, Bruz, France

\section{*Corresponding author}

Frédéric Derbré, Assistant professor, PhD , Email: frederic.derbre@univ-rennes2.fr

\section{Pemanent adress}

Laboratory "Movement Sport and health Sciences-M2S", Rennes 2 University -ENS Rennes Av. Robert Schuman - Campus Ker-Lann, 35170 Bruz - France, Phone: (33) 290091583

\begin{abstract}
In the literature, the terms physical inactivity and immobilization are largely used as synonyms. The present review emphasizes the need to establish a clear distinction between these two situations. Physical inactivity is a behavior characterized by a lack of physical activity, whereas immobilization is a deprivation of movement for medical purpose. In agreement with these definitions, appropriate models exist to study either physical inactivity or immobilization, leading thereby to distinct conclusions. In this review, we examine the involvement of oxidative stress in skeletal muscle insulin resistance and atrophy induced by, respectively, physical inactivity and immobilization. A large body of evidence demonstrates that immobilization-induced atrophy depends on the chronic overproduction of reactive oxygen and nitrogen species (RONS). On the other hand, the involvement of RONS in physical inactivity-induced insulin resistance has not been investigated. This observation outlines the need to elucidate the mechanism by which physical inactivity promotes insulin resistance.
\end{abstract}

\section{INTRODUCTION}

The terms physical inactivity and immobilization are a source of confusion in the literature. Most of the conclusions drawn on physical inactivity are based on results from immobilization experiments [1, 2]. Physical inactivity is a behavior characterized by a lack of physical exercise, whereas immobilization is a clinical state in which one limb or whole body 
is mechanically unloaded. Although immobilization belongs to the continuum of physical inactivity, it is an extreme situation, requiring a distinct experimental design. On the one hand, immobilization is investigated in human through several models such as bed rest, casting and unilateral lower limb suspension. In rodents, hindlimb unloading remains the reference model of immobilization [3]. On the other hand, physical inactivity is experimentally reproduced with the reduction of the daily number of steps from 10,000 to 1,500-3,000 in human or with the locked-wheel model in rodents [4, 5]. From physical inactivity to immobilization, decline of muscle load promotes insulin resistance and atrophy $[6,7]$, pathological states in which the overproduction of reactive oxygen and nitrogen species (RONS) seems a common denominator [8, 9]. Herein, we will focus this review on the role of RONS on skeletal muscle insulin resistance and atrophy in the context of physical inactivity and immobilization. To avoid confusion, we chose to make a clear distinction between physical inactivity and immobilization (see Figure 1).

\section{Physical inactivity: definition, causes and consequences}

Physical inactivity is basically defined as a lack of physical activity [10]. The World Health Organization (WHO) established a threshold, separating inactive vs. active humans, based on the metabolic equivalent of task (MET), one MET being the minimum power required to maintain the basal metabolism. According to WHO, active adult performs at least 150 minutes of moderate-intensity (3.0-5.9 MET) physical activity per week or at least 75 minutes of vigorous-intensity $(\geq 6.0$ MET) physical activity per week or an equivalent combination of moderate- and vigorous-intensity activity achieving 600 MET-minutes score per week [11]. In children and adolescents (5-17 years old), physical inactivity is defined as not meeting 60 minutes of moderate to vigorous-intensity physical activity daily [11]. Based on these definitions, the worldwide prevalence of physical inactivity reaches $31 \%$ in adults and $80 \%$ in adolescents [12]. This high proportion of inactive people contrasts with the singular capacity of human for long endurance exercises [13].

In the genus Homo, a high level of physical activity was an adaptive behavior required for food procurement, escape from predators, social interactions and search for shelter. During the last two centuries, the scientific progress radically changed conditions which drove hominid evolution for 7 million years. By replacing human work with machines, the industrial revolution initiated a drastic reduction of physical activity. Since then, the development and democratization of new technologies have strengthened this phenomenon. In modern society, physical activity, instead of vital, became a leisure which is not practiced by a large part of the 


\section{ACCEPTED MANUSCRIPT}

population. In the beginning of the $20^{\text {th }}$ century, the sedentary behavior was firstly encouraged by the scientific community which pointed out the hazards of exercise [14]. A turning point operated when, in 1953, Morris and Heady published a large scale epidemiological study highlighting the deleterious effect of physical inactivity on health. In this study, the authors concluded: "physical work may be a way of life conducive to good health" [15].

First seen as a progress, the reduction of physical activity is now recognized as a major factor contributing to the burden of non-communicable diseases [12]. After smoking, physical inactivity is the second risk factor for non-communicable diseases, responsible for 5.3 million deaths per year worldwide [16]. In addition, Pedersen proposed a "diseasome of physical inactivity", gathering cardiovascular disorders, different types of cancer, type 2 diabetes, depression and dementia [4]. Worldwide, Lee et al. [16] estimate that physical inactivity causes $6 \%$ of the coronary heart disease, $7 \%$ of type 2 diabetes and $10 \%$ of breast and colon cancers. Among these diseases, the most alarming is likely type 2 diabetes, a pathological state characterized by insulin resistance. In the United States, diabetes affects $9.3 \%$ of the population and the total cost reaches 245 billion dollars per year [17].

\section{Immobilization: definition, causes and consequences}

Immobilization is a deprivation of movement for medical purpose of either a limb or whole body. It is noteworthy that the cause is independent of the will and the consequences on biology are almost immediate, thus contrasting with physical inactivity. Due to medicine progress and aging of the population, more and more people are immobilized in hospital or at home. In the United States, hospitalization related to aging increased by $11.8 \%$ between 2005 and 2015 [18]. For instance, osteoporotic hip fracture is estimated to reach 300,000 cases annually in the United States [19]. Given that the proportion of elderly will increase, the number of hospitalizations is expected to rise in the future [20].

Whatever the cause, the major complication for bedridden patients is the rapid development of skeletal muscle atrophy [21-23], a collateral damage which poses challenging health issues. Indeed, skeletal muscle atrophy is associated with a loss of strength, a situation which promotes functional deficits, exacerbates illness and complicates patient recovery, especially in the elderly [24]. In this population, immobilization constitutes a major risk factor for functional decline and loss of autonomy [25]. Consequently, the prevention of skeletal muscle atrophy is crucial for patients, medical team and healthcare system [24, 26]. 


\section{ACCEPTED MANUSCRIPT}

\section{SKELETAL MUSCLE OXIDATIVE STRESS IN IMMOBILIZATION AND PHYSICAL INACTIVITY}

Source of RONS in skeletal muscle

From immobilization to strenuous physical exercise, RONS production in skeletal muscle follows a U-shaped curve [27]. This representation brings out the RONS paradox, good friends when associated with physical activity but bad guys when induced by an absence of physical activity. Herein, we will present the main mechanisms leading to RONS production in skeletal muscle.

Sequential univalent reduction of dioxygen produces oxidant molecules collectively named reactive oxygen species (ROS). The primary ROS generated, superoxide $\left(\mathrm{O}_{2}{ }^{-}\right)$, gives rise to others ROS, e.g., hydrogen peroxide $\left(\mathrm{H}_{2} \mathrm{O}_{2}\right)$ and the highly toxic hydroxyl radical (HO•). In skeletal muscle, ROS are produced by: 1) mitochondria; 2) nicotinamide adenine dinucleotide phosphate (NADPH) oxidase (NOX); 3) phospholipase A2 (PLA2); 4) xanthine oxidase (XO); 5) endoplasmic reticulum (ER).

In the mitochondria, electrons from $\mathrm{NADH}$ and $\mathrm{FADH}_{2}$ are transferred from electron donor to electron acceptor molecules in a process coupled with energy production. Electrons are transported through four enzymatic complexes (I, II, III, IV) known as electrons transport chain. During this process, a small part of the electrons leaks, mainly through complex I, reduced dioxygen thus leading to $\mathrm{O}_{2}{ }^{-}$formation [28]. According to in vitro experiments, it has been proposed that $0.12-2 \%$ of dioxygen consumed by mitochondria is converted into $\mathrm{O}_{2}{ }^{-}$ [28]. However, these values cannot be generalized to the in vivo situation, and depend on several factors such as oxidized substrate, mitochondria respiratory states, fiber types and electron donor concentration [27, 28]. Whatever the exact proportion of dioxygen converted into $\mathrm{O}_{2}{ }^{-}$, mitochondria is a major source of ROS in skeletal muscle [29].

The enzymatic complex NOX catalyzes the NADPH-dependent reduction of dioxygen to produce $\mathrm{O}_{2} \cdot$. In immune cells such as neutrophils and macrophages, NOX2 (also called gp91phox) is used as a «superoxide gun» to kill pathogens during phagocytosis [30]. In addition to the phagocyte NOX2, six non-phagocytic NOXs have been identified: NOX1, NOX3, NOX4, NOX5, DUOX1 and DUOX2 [31]. Skeletal muscle expressed NOX2 and NOX4, located in the sarcoplasmic reticulum, the sarcolemma and transverse tubules [29, 32]. It has been reported that NOX4 is constitutively active and directly produces hydrogen peroxide [33]. Although NOXs contributes to skeletal muscle ROS production both at rest and during exercise, their physiological functions remain unidentified in myocytes. 
PLA2 hydrolyses membrane phospholipid and releases arachidonic acid. This lipid serves as a substrate for the lipoxygenases, a reaction coupled with the reduction of dioxygen into $\mathrm{O}_{2} \bullet^{-}$[34]. Furthermore, PLA2 could stimulate NOXs and mitochondria $\mathrm{O}_{2} \bullet^{-}$production [27]. Gong et al. proposed that PLA2-dependent process generates $\mathrm{O}_{2}{ }^{{ }^{-}}$in skeletal muscle under resting and exercise conditions [35].

$\mathrm{XO}$ and xanthine dehydrogenase $(\mathrm{XDH})$ are isoenzymes of xanthine oxidoreductase (XOR), whose activities have been well identified during ischemia-reperfusion phenomenon. During ischemia, energy-starved tissues catabolize ATP to hypoxanthine. Calcium activates specific proteases which convert $\mathrm{XDH}$ to $\mathrm{XO}$ by cleavage. Then, $\mathrm{XO}$ catalyzes the oxidation of hypoxanthine and xanthine to produce respectively xanthine and acid uric, these reactions are coupled with the reduction of dioxygen into $\mathrm{O}_{2}{ }^{-}$. Interestingly, $\mathrm{XO}$ is likely a major source of ROS in skeletal muscle during exercise [36]. However, in this tissue, XO seems present in capillary endothelium and infiltrated leucocytes rather than in myocytes [37].

ER lumen is highly oxidant compared to cytosol [38], this unique environment allows the formation of disulfide bonds, a process generating ROS. Inside the ER, electrons from oxidized thiol groups are accepted by the protein disulfide isomerase and then transferred to the endoplasmic reticulum oxidoreductin-1-like protein (ERO1). Finally, ERO1 transfers electrons to oxygen and produces $\mathrm{H}_{2} \mathrm{O}_{2}$ [39]. Although this source of ROS is usually not mentioned, it has been estimated that ER could be responsible for up to $25 \%$ of ROS generated during protein synthesis [40].

The primary reactive nitrogen species $(\mathrm{RNS})$ generated, nitric oxide $(\cdot \mathrm{NO})$, give rises to others RNS such as nitrogen dioxide $\left(\cdot \mathrm{NO}_{2}\right)$ and the highly aggressive peroxynitrite (ONOO${ }^{-}$ ). In the cells, $\cdot \mathrm{NO}$ is mainly synthetized from L-arginine, a reaction catalyzed by enzymes belonging to the nitric oxide synthase (NOS) family. In skeletal muscle, three NOS are expressed: 1) neuronal NOS (NOS1 or nNOS); 2) inducible NOS (NOS2 or iNOS); 3) endothelial NOS (NOS3 or eNOS). In skeletal muscle, NOS1 and NOS3 are constitutively expressed while NOS2 is mainly found under inflammatory condition [41]. NOS1 is typically present in the sarcolemma linked to the dystrophin complex, whereas NOS3 seems localized in the mitochondria [27, 42]. When expressed, NOS2 is likely localized in the cytosol [43]. It is noteworthy that localization of NOSs in skeletal muscle is still under debate. Indeed, NOS1 has also been found in the sarcoplasm and the Golgi apparatus, whereas identification of the mitochondrial NOS remains controversial [41]. 
In physiological conditions, RONS are signaling molecules, involved in essential processes such as insulin action, immune response, apoptosis, autophagy, mitochondria biogenesis and differentiation [8, 29, 41]. On the other hand, continuous and high concentration of RONS induces oxidative and irreversible damage to proteins, lipids, RNA and DNA. In skeletal muscle, oxidation of these biomolecules participates in the development of insulin resistance and atrophy [44, 45]. Thus, an efficient antioxidant system is required to maintain RONS concentration in a physiological range.

\section{Antioxidant defense in skeletal muscle}

Antioxidant defense gathers enzymatic and non-enzymatic systems, acting in a complementary manner within cells, extracellular and vascular space. The enzymatic defenses mainly include superoxide dismutase (SOD), catalase and glutathione peroxidase (GPx), whereas non-enzymatic defenses include multiple molecules such as reduced glutathione (GSH), vitamin E and vitamin C.

In mammals, three isoforms of SOD have been identified: SOD1, SOD2 and SOD3. SOD1 is present in the cytosol and the mitochondrial intermembrane space, SOD2 is found in the mitochondrial matrix and SOD3 is localized in the extracellular space [27]. SOD1/SOD3 and SOD2 use, respectively, copper-zinc and manganese as a co-factor. By catalyzing the dismutation of $\mathrm{O}_{2}{ }^{-}$into $\mathrm{H}_{2} \mathrm{O}_{2}$, SOD limits $\mathrm{O}_{2}{ }^{-}$content. However, the product of this reaction, $\mathrm{H}_{2} \mathrm{O}_{2}$, can exert a wide range of deleterious effects due to its relative long half-life and high diffusion capacity [29]. Thus, $\mathrm{H}_{2} \mathrm{O}_{2}$ concentration must be tightly limited in the cells.

The removal of $\mathrm{H}_{2} \mathrm{O}_{2}$ is performed by both catalase and GPx [46]. Catalase requires heme iron as a co-factor to convert $\mathrm{H}_{2} \mathrm{O}_{2}$ into water and dioxygen [47]. This enzyme is widely distributed in the cell but predominates in peroxisomes [27, 48]. GPx catalyzes the reduction of $\mathrm{H}_{2} \mathrm{O}_{2}$ into water by using an electron donor, GSH, which is converted into its oxidized form GSSG. GPX is mainly localized in cytosol and mitochondria [27]. It is noteworthy that, compared to the glycolytic fibers, the oxidative fibers contain a higher level of SOD, catalase and GPx [49].

A wide range of non-enzymatic antioxidants are present in cells (e.g., GSH, vitamin C, vitamin $\mathrm{E}$ and $\beta$-carotene), only GSH will be mentioned herein. Ubiquitous and present in all parts of the cells, the tripeptide GSH is a major antioxidant [50]. As aforementioned, GSH serves as a substrate in the reaction catalyzed by GPx but it is also a reducing agent which exerts a direct antioxidant action. In addition, GSH allows the recycling of vitamin $\mathrm{E}$ and $\mathrm{C}$, thus maintaining their antioxidant power [49]. 
Skeletal muscle oxidative stress in immobilization and physical inactivity

Oxidative stress has been extensively studied in skeletal muscle, especially during exercise [27], and more recently during immobilization [51]. In contrast, much less attention has been paid to alteration of the redox system induced by physical inactivity. It is noteworthy that, studies comparing sedentary behavior to lifelong exercise will not be discussed in this review. Indeed, those ways of life are studied in the context of aging, a process well-known to promote oxidative stress. Thus, aging constitutes a cofounding factor preventing to isolate the effects of physical inactivity on oxidative stress. For the same reason, studies dealing with aging and immobilization will not be discussed in this review. To the best of our knowledge, no studies characterized the effects of physical inactivity on muscle oxidative stress. Consequently, we will focus on the effects of immobilization on muscle oxidative stress.

Data from animals, and more recently from humans, indicate that immobilization increases $\mathrm{O}_{2}{ }^{-}$and $\mathrm{H}_{2} \mathrm{O}_{2}$ emissions in skeletal muscle [52-56]. Mitochondria contributes to muscle ROS production during immobilization [52, 54-56], but other studies highlight that XO plays also an important role $[57,58]$. To the best of our knowledge no studies reported that NOX, NOS or ER plays a role in the production of ROS induced by immobilization. ROS production promotes the activation of non-enzymatic and enzymatic antioxidant systems. On one hand, the ratio GSH/GSSG decreases in skeletal muscle during hindlimb unloading [5961]. On the other hand, immobilization causes, in skeletal muscle, an increase of SOD1 and catalase protein content and activities [53, 57, 59, 61-64], whereas SOD2 protein content and activity do not change [61, 63-65].

Although immobilization increases ROS production and upregulates antioxidant defenses, the effects on macromolecular damage are less clear. Carbonylation of proteins is frequently measured to determine oxidative damage during immobilization. The few studies conducted in human observed that carbonylated protein levels did not change in the vastus lateralis after 8 and 14 days of bed rest [66, 67], but became higher after 35 days [66]. In rodents, some studies reported an increase of carbonylated proteins in the soleus during the first week of hindlimb unloading [57, 68-70], whereas other reports did not observed such effect after 3, 7 and 14 days of hindlimb unloading [53, 60, 62]. A more restricted number of studies focused on the effects of immobilization on $\alpha, \beta$-unsaturated aldehydes (e.g., 4-HNE, MDA), markers of lipid peroxidation. 4-HNE content increased in rat soleus after 8 days of hindlimb unloading [64, 71], whereas elevations in MDA and TBARS contents were reported after 10 and 14 days of hindlimb unloading, respectively [61, 69]. All together, these results 
suggest that immobilization first induced lipid peroxidation and later protein carbonylation in skeletal muscle. In this context, elevation of 4-HNE level could be an early event contributing to protein carbonylation via Michael addition cascade [72].

Presently, oxidative stress is no longer seen as disequilibrium between pro- and antioxidant. Indeed, this reductive approach implies that oxidative stress depends on a single balance, thus setting aside the diversity and complexity of the redox system. To bypass this difficulty, oxidative stress is currently defined from its endpoint: "macromolecular damage, and disruption of thiol redox circuits, which leads to aberrant cell signaling and dysfunctional redox control" [73]. Based on this definition, data presented in this section lead us to conclude that immobilization induces oxidative stress in skeletal muscle.

\section{ROLE OF OXIDATIVE STRESS IN IMMOBILIZATION-INDUCED SKELETAL MUSCLE ATROPHY}

Cellular mechanisms involved in immobilization-induced skeletal muscle atrophy

Myocytes are postmitotic cells like neurons or cardiomyocytes, whose size are de facto regulated by the balance between protein synthesis and degradation. Despite the debate concerning the dominant mechanism of immobilization-induced muscle atrophy [74], the scientific community agrees that protein turnover is altered in this pathological process.

Immobilization causes a rapid decrease of protein synthesis in rodent and human skeletal muscle. Indeed, numerous studies demonstrated that a reduction in muscle protein fractional synthesis rate (FSR) occurs in the first days of immobilization [53, 75, 76]. This rapid reduction of protein synthesis persists for several weeks since a decrease of muscle FSR has been also reported in human skeletal muscle after 14 and 28 days of bed rest [77, 78]. Protein synthesis is mainly modulated at the translation level through the PI3K (phosphatidyl inositol 3-kinase)/Akt/mTORC1 (mammalian target of rapamycin) pathway [79]. Specifically, mTORC1 enhances the formation of the 40S ribosomal subunit through the phosphorylation of the $4 \mathrm{E}$ binding protein 1 (4E-BP1) and the ribosomal protein S6 kinase (S6K). Phosphorylation of 4E-BP1 and S6K induce their activation and dissociation from eukaryotic initiation factor 4E (eIF4E) and eIF3, respectively, allowing the formation of the 40S ribosomal subunit. Interestingly, skeletal muscle exhibits alteration in PI3K/Akt/mTORC1 axis during immobilization [75, 76, 80-82]. This phenomenon, called anabolic resistance, emphasizes the reduced response to anabolic stimuli [80, 82].

Under apoptosis, the loss of myonuclei is another mechanism proposed to explain the reduced ability of myocytes to synthetize proteins during immobilization [83]. In myocytes, a 


\section{ACCEPTED MANUSCRIPT}

decrease number of nuclei reduces the transcriptional activity in the surrounding domain of cytoplasm of each nucleus (i.e., myonuclear domain), and therefore reduces the overall protein synthesis capacity [84]. In myonuclei, DNA fragmentation has been reported in rodent during the first days of hindlimb unloading using histological TUNEL staining [85-88]. This suggests that apoptosis would be a biological process promoting atrophy through a loss of myonuclei during immobilization. Such idea is supported by studies demonstrating that caspase-3 activity [59, 89] and the apoptotic mitochondrial intrinsic pathways (i.e., endonuclease $\mathrm{G}$ and apoptosome) [86, 90] are stimulated in unloaded skeletal muscle. However, these results have been challenged [91]. Using an in vivo time-lapse microscopy to quantify myonuclei in single muscle fibers, Gundersen and Bruusgaard showed that 14 days of hindlimb unloading were not accompanied by a loss of nuclei [91]. Their convincing experiment highlighted that, the histological TUNEL staining may lead to confound myonuclear and nuclei from stromal/satellite cells [91]. Additional experiments are needed to determine whether immobilization does result in a loss of myonuclei.

Proteolysis plays a major role in immobilization-induced skeletal muscle atrophy. Calpains, caspase-3, ubiquitin-proteasome and autophagy-lysosome systems act synergistically to stimulate protein breakdown in unloaded skeletal muscle. Although a loss of sarcoplasmic proteins occurs, myofibrillar proteins are the main target of proteolysis during immobilization [92]. The calpains and caspase-3 are key proteases that initiate muscle proteolysis by degrading sarcomeres. Indeed, calpains breakdown structural proteins like titin, nebulin or $\alpha$-fodrin [93], whereas caspase-3 targets intact actomyosin [94]. The breakdown of sarcomeric proteins releases actin and myosin, which in turn are degraded by the ubiquitin proteasome system (UPS). In skeletal muscle, recent studies demonstrated that both calpains and caspase-3 were activated by hindlimb unloading [59, 95, 96]. Interestingly, pharmacological inhibition of calpains or caspase-3 prevents type I fibers atrophy observed in casted rats, demonstrating that these proteases are mandatory for skeletal muscle atrophy [89]. These results also suggest that activation of caspase-3 signaling pathway contributes to skeletal muscle atrophy independently from a loss of myonuclei.

Once calpains/caspase-3 system initiates the sarcomeres disassembly, the myofibrillar proteins are ubiquinated and degraded by the 26S proteasome complex. The ubiquitinactivating enzyme (E1) activates ubiquitin, which is then transferred to the ubiquitin conjugating protein (E2). The E2 enzyme interacts with an ubiquitin ligase (E3) which catalyzes the transfer of ubiquitin to the target protein, marking it for proteasomal degradation. The muscle RING finger 1 (MurF1) and muscle atrophy F-box (MAFbx) are the 


\section{ACCEPTED MANUSCRIPT}

main ubiquitin ligases responsible for protein degradation in skeletal muscle. It is well established that immobilization causes an accumulation of polyubiquitinated proteins in rodent and human skeletal muscle [96-98] due to increase in both MuRF-1 and MAFbx expression [53, 57, 62, 99]. The nuclear factor- $\kappa \mathrm{B}(\mathrm{NF}-\kappa \mathrm{B})$ directly regulates the transcription of MuRF1, and consequently plays an important role in immobilization-induced protein degradation [100, 101]. On the one hand, activation of the NF- $\mathrm{B}$ p65-p50 heterodimer is regulated through its release from $\mathrm{I} \kappa \mathrm{B} \alpha$, thus leading to its nuclear translocation (canonical pathway). On the other hand, BCL-3 binding to the NF- $\kappa \mathrm{B}$ p50-p50 homodimer is an

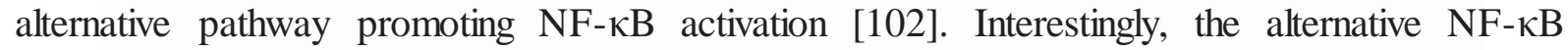
signaling is required for immobilization-induced skeletal muscle atrophy [102-104], this may be not the case for the canonical NF- $\mathrm{BB}$ signaling [102]. The Forkhead box subfamily O (FOXO) transcription factors regulate the transcription of MAFbx [105, 106], but their role in MuRF-1 expression is still under debate [101, 107, 108]. Interestingly, hindlimb unloading stimulates FOXO1A and FOXO3A activities in rodent skeletal muscle [81, 101, 109], whereas results from unilateral lower limb suspension experiments are less consistent in human [110, 111]. The radical model used in rodent, i.e., hindlimb suspension, could explain the discrepancy with human experiment.

In skeletal muscle atrophy, the autophagy-lysosome system operates in a complementary manner with UPS. Autophagy is a process characterized by the formation of a doublemembrane vesicle (autophagosome) engulfing cytoplasmic components. Subsequently, autophagosome fuses with lysosomes for digestion [112]. This process is regulated by more than 30 autophagy-related (Atg) genes. The autophagosome formation is initiated by the small ubiquitin-like molecules [microtubule-associated proteins 1A/1B light chain 3A (LC3), GABARAP, GATE16 and Atg12]. The latter are activated by E1 enzyme (Atg7) and transferred to E2 enzymes (Atg 3 or Atg10). Then, small ubiquitin-like molecules are transferred via Atg12-Atg5-Atg16 complex to membranes, which then grow leading to autophagosome formation [112]. Autophagy constitutes a quality control mechanism, ensuring cell homeostasis and functions. However, its hyperactivation leads to cellular dysfunctions and exacerbates muscle loss in atrophying conditions [113]. In skeletal muscle, myofibrillar proteins targeted by ubiquitin can have a double fate: 1) recognized and removed by the proteasome $26 \mathrm{~S}$ or 2) docked to the autophagosome. In the latter case, polyubiquitin chains interact with the ubiquitin binding protein p62 which possesses an interaction domain with LC3. This mechanism brings then ubiquitinated proteins to the growing autophagosome. Interestingly, Cannavino and colleagues reported an elevation of p62 mRNA in the soleus of 


\section{ACCEPTED MANUSCRIPT}

mice after one week of hindlimb unloading [53, 62]. Moreover, hindlimb unloading and casting caused, in skeletal muscle, an increase of LC3 ratio (LC3II/I) [54, 60], a marker of autophagy activation. Data in human are scarce and less consistent [114]. All together, the results suggest that autophagy plays a role in skeletal muscle loss during immobilization.

Evidence for a role of RONS in immobilization-induced skeletal muscle atrophy

In vitro and in vivo evidence strongly support the involvement of RONS in skeletal muscle atrophy [115-119]. In the last decade, studies demonstrated that oxidant molecules $\left(\mathrm{H}_{2} \mathrm{O}_{2}\right.$ and doxorubicin) stimulate ubiquitin conjugation, upregulated E2 enzyme, MAFbx and MuRF-1 gene expression in C2C12 myotubes [118, 120]. Specifically, RONS-dependent p38 phosphorylation mediates MAFbx expression [115, 119], whereas molecular mechanisms by which RONS regulate MuRF-1 expression remain unknown. RONS have been also identified as mediators for activation of the calpain system. Using small interfering RNA in C2C12 myotubes, Talbert and colleagues have demonstrated that, among the different proteases, calpain-1 was required for $\mathrm{H}_{2} \mathrm{O}_{2}$-induced $\mathrm{C} 2 \mathrm{C} 12$ myotubes atrophy [117]. As previously described, myonuclear apoptosis is thought to play a role in skeletal muscle atrophy. In C2C12 myotubes, $\mathrm{H}_{2} \mathrm{O}_{2}$ induces DNA fragmentation mediated by $\mathrm{Bax}$ upregulation, mitochondrial cytochrome c and apoptosis-inducing factor releases [116], a result supporting that RONS overproduction stimulates apoptosis during immobilization.

In vivo, recent studies support that UPS and autophagy are regulated in a redoxdependent manner. In skeletal muscle of rats, catalase overexpression prevented immobilization-induced skeletal muscle atrophy [121]. Interestingly, this effect was associated with a reduction of FOXO and NF- $\mathrm{BB}$ activation. These results have been confirmed by using antioxidant agents such as EUK-134 (SOD and catalase mimetic) [71] and SS-31 (mitochondria-targeted antioxidant) [54, 121]. The inhibition of mitochondrial ROS production prevented soleus atrophy and UPS/autophagy activation induced by casting [54], whereas EUK-134 limited skeletal muscle atrophy and FOXO3a activation induced by hindlimb unloading [71]. Taken together, these data support that RONS activate UPS and autophagy in immobilization-induced skeletal muscle atrophy. As previously pointed out, xanthine oxidase is an important source of ROS in skeletal muscle during immobilization [57, 65]. Using allopurinol, an inhibitor of xanthine oxidase, our laboratory demonstrated that this strategy partially prevented hindlimb unloading-induced skeletal muscle loss in rats through a mechanism involving the p38-MAFbx axis [57]. However, these results contrast with a previous study conducted in mice [122], emphasizing the need for further researches. 


\section{ACCEPTED MANUSCRIPT}

The use of non-pharmacological antioxidants has also been tested to prevent skeletal muscle atrophy. Vitamin E and analogs appeared as compounds which prevent muscle atrophy induced by immobilization [58, 61, 123]. Specifically, vitamin E would counteract muscle atrophy by reducing expression of proteases (caspase-3 and calpains), MuRF-1 and MAFbx [61]. Other dietary antioxidant compounds have been recently proposed to prevent hindlimb unloading-induced skeletal muscle atrophy. In rats, resveratrol supplementation partially prevents skeletal muscle atrophy induced by 14 days of hindlimb unloading [124]. The effects of curcumin supplementation on muscle atrophy have been also assessed in both mice and rats. Vitadello and colleagues observed, in rats, that daily curcumin injections prevented muscle atrophy induced by 10 days of hindlimb unloading [69], whereas others did not report any preventive effects in suspended mice fed with a curcumin supplemented diet [125]. These contradictory results underscore that dose and mode of administration may modulate the effectiveness of antioxidant agents.

All together, these results highlight that antioxidant supplementation could be a promising strategy to prevent skeletal muscle atrophy during immobilization. However, additional studies are needed to test whether antioxidant supplementations prevent muscle atrophy in bedridden or casted patients. The Figure 2 illustrates the mechanism of RONSinduced skeletal muscle atrophy in immobilization.

\section{ROLE OF OXIDATIVE STRESS IN PHYSICAL INACTIVITY-INDUCED SKELETAL MUSCLE INSULIN RESISTANCE}

Regulation of insulin-dependent glucose uptake in skeletal muscle

Insulin resistance is defined as an inadequate response to insulin in target tissues. In skeletal muscle, insulin resistance results in a reduced ability of insulin to stimulate glucose uptake. Given that skeletal muscle accounts for $\sim 80 \%$ of insulin-mediated glucose uptake [126], alteration of insulin action in myocytes plays a key role in hyperglycemia, the hallmark of type 2 diabetes.

In skeletal muscle, regulation of glucose uptake by insulin is mediated by several effectors and culminates with the translocation of glucose transporter 4 (GLUT4) to the membrane, thus allowing the entry of glucose into myocytes (Figure 3). Insulin is the master regulator of glycemia in post-prandial state. After a meal, increase of glycemia stimulates insulin secretion by the pancreatic $\beta$-cells. Insulin binds to its transmembrane receptor, the insulin receptor (IR). IR is a heterotetramer composed by two extracellular $\alpha$ subunits and two transmembrane $\beta$ subunits linked to each other by disulfide bridges [127]. Insulin interaction 
with the $\alpha$ subunits activates the tyrosine kinase domain of the $\beta$ subunits, resulting in autophosphorylation of several tyrosine residues located in the juxtamembrane region and intracellular C-tail [128]. Tyr ${ }^{960}$ of IR is a key residue for the regulation of insulin-stimulated glucose transport [128]. This docking site recruits proteins which contain a phosphotyrosine binding (PTB) domain. Among these proteins, the insulin receptor substrates 1 and 2 (IRS-1 and IRS-2) mediate most of the insulin effects. IRS-1/2 contains a PTB domain next to a pleckstrin homology $(\mathrm{PH})$ domain [129]. Due to its high affinity for phospholipids, the $\mathrm{PH}$ domain of IRS-1/2 stabilizes the protein at the membrane and facilitates the phosphorylation of its PTB domain by IR. Phosphorylated IRS-1/2 on tyrosine residue recruits the regulating subunit (p85) of PI3K through its Src homology 2 domain. This interaction leads to the activation of PI3K catalytic subunit (p110), which catalyzes the formation of the membrane phospholipid phosphatidylinositol 3,4,5-trisphosphate ( $\left.\mathrm{PIP}_{3}\right)$ from phosphatidylinositol 4,5diphosphate $\left(\mathrm{PIP}_{2}\right)$ [127]. $\mathrm{PIP}_{3}$ recruits Akt and phosphoinositide-dependent kinase-1 (PDK1) to the membrane through their $\mathrm{PH}$ domains. The serine/threonine kinase Akt contains a $\mathrm{PH}$ domain in its $\mathrm{N}$-terminal end, a kinase domain and a C-terminal hydrophobic domain. In mammalian, three isoforms of Akt have been identified: Akt1, Akt2 and Akt3. Akt1 is widely expressed, whereas Akt3 is principally found in brain and testes. Akt2 expression is predominant in adipocytes and myocytes, where it is responsible for glucose uptake [130]. In the cytosol, Akt is maintained in an inactive state through an association between its kinase and $\mathrm{PH}$ domains. When recruited to the membrane by $\mathrm{PIP}_{3}$, Akt is phosphorylated by PDK1 and mammalian target of rapamycin complex 2 on $\mathrm{Thr}^{308}$ (kinase domain) and $\mathrm{Ser}^{473}$ (Cterminal domain), respectively. Akt activity increases by 100-fold when phosphorylated on $\mathrm{Thr}^{308}$, but full activation requires $\mathrm{Ser}^{473}$ phosphorylation [130]. Activated Akt returns to the cytosol and phosphorylates the TBC1 family member 1 (TBC1D1) and 4 (TBC1D4, formerly known as Akt substrate 160, AS160). TBC1D1/TBC1D4 proteins exhibit GTPase activity toward several G proteins, namely Rab, which are associated with GLUT4 storage vesicles (GSVs). This GTPase activity is inhibited by Akt phosphorylation, leading to an increase of the active forms of Rab, i.e., Rab GTP-bound form [131]. Activated Rab promotes all the steps of GLUT4 exocytosis: approach, tethering, docking and fusion [132].

Upon insulin stimulation, the cytoskeleton provides tracks for the displacement of GSVs and insulin effectors such as IRS-1/2, PI3K and Akt. Recently, cytoskeletal reorganization appeared as an essential step of insulin-mediated glucose uptake, a process involving the $G$ protein Rac1 in myocytes [133]. 


\section{ACCEPTED MANUSCRIPT}

\section{Physical inactivity causes skeletal muscle insulin resistance}

Insulin resistance is generally diagnosed in fasting state via the homeostasis model assessment-estimated insulin resistance (HOMA-IR) [134], or with the Matsuda index in the dynamic state [135]. Using these clinical tools, numerous epidemiological and experimental studies have clearly demonstrated, in human, that physical inactivity promotes insulin resistance [136-140]. Based on the physical inactivity threshold determined by the WHO, the epidemiological RISC and ATTICA studies highlighted that physically inactive people exhibited higher HOMA-IR values, and this was independent from the body mass index [136, 137]. Human experimental studies confirmed these data by demonstrating that a reduction of daily steps from more than 10,000 to less than 1,500 steps/day increased the HOMA-IR and Matsuda index after only 5 days [139, 140]. Specifically, reduction in daily steps during 14 days has been associated with peripheral insulin resistance and inhibition of insulin-stimulated Akt phosphorylation in skeletal muscle [141]. In rodents, similar results have been reported by using the locked-wheel model. Indeed, a reduction in insulin-stimulated glucose uptake was observed in skeletal muscle 53h after cessation of physical activity [142]. Interestingly, alteration in muscle glucose uptake was associated with a reduction of GLUT4 protein content, IR-tyrosine and Akt phosphorylations [142]. Unfortunately, studies exploring the cellular mechanisms responsible for physical inactivity-induced muscle insulin resistance are scarce [143].

\section{Evidence for a role of RONS in skeletal muscle insulin resistance}

At a cellular level, insulin resistance is a transduction defect of the insulin signaling. The physiopathology of insulin resistance remains difficult to apprehend since it results from a complex integration of diverse cellular disorders: inflammation [144], intra/extracellular lipids accumulation [145, 146], mitochondrial dysfunction [147] and oxidative stress [8]. However, a large body of evidence highlights that disruption of redox homeostasis could be a common factor by which these cellular disorders inhibit insulin signaling [148, 149]. In L6 myotubes, SOD mimetic or SOD overexpression reduced insulin resistance induced by the tumor necrosis factor $\alpha$ (TNF $\alpha)$, chronic insulin or dexamethasone [150]. In addition, palmitate-induced insulin resistance in L6 myotubes was prevented by two chemical agents which reduce mitochondrial superoxide production [150]. In leptin-deficient ob/ob mice, SOD mimetic improved whole-body insulin sensitivity [151]. As described herein, considerable evidence shows that oxidative stress is a central player in the development of insulin resistance. In the literature, several mechanisms have been proposed, they include: 1) IRS-1/2 


\section{ACCEPTED MANUSCRIPT}

serine phosphorylation; 2) reduction of GLUT4 protein expression; 3) alteration of the molecular traffic required for insulin action; 4) insulin effectors oxidation.

The mechanism by which oxidative stress induces insulin resistance is mainly based on IRS-1/2 serine phosphorylation caused by the redox-sensitive kinases p38, c-Jun aminoterminal kinase (JNK), IKB kinase $\beta$ (IKK $\beta$ ) and extracellular signal-regulated kinases (ERK1/2) [152]. IRS-1/2 serine phosphorylation enhances its degradation and reduces its tyrosine phosphorylation, inhibiting de facto the insulin signaling [8]. In addition, oxidative stress activates $\mathrm{NF}-\kappa \mathrm{B}$ which in turn upregulates $\mathrm{TNF} \alpha$, an inflammatory cytokine inhibiting insulin signaling through IKK $\beta$ activation [153]. However, caution must be taken when generalizing these mechanisms to skeletal muscle. Muscle-specific JNK or IKK $\beta$ deficient mice were not protected against obesity-induced insulin resistance [154, 155]. In addition, overactivation of NF- $\mathrm{KB}$ and IKK $\beta$ in skeletal muscle does not lead to insulin resistance [156]. Finally, the role of IRS-1/2 serine phosphorylation in the development of insulin resistance has been challenged $[157,158]$. In skeletal muscle, more studies are needed to determine the implication of $\mathrm{p} 38$, JNK, IKK $\beta$, ERK and NF- $\mathrm{BB}$ in oxidative stress-induced insulin resistance.

The downregulation of GLUT4 protein expression is a proposed mechanism by which oxidative stress disrupts insulin sensitivity [44]. Although that seems relevant in adipose tissue $[8,159,160]$, this is not the case in skeletal muscle. Indeed, GLUT4 protein expression is, in most of the cases, unaltered in skeletal muscle of type 2 diabetic patients despite evidence for oxidative stress [161, 162]. In addition, exercise (single bout or training) is well known to stimulate both GLUT4 expression and RONS production in skeletal muscle [163]. Consequently, oxidative stress seems unlikely associated with GLUT4 downregulation in skeletal muscle.

As described above, activation of some insulin effectors requires their displacement from one subcellular compartment to another. Some studies reported that such protein movements are redox-sensitive. In skeletal muscle of rats, insulin-stimulated subcellular redistribution of tyrosine-phosphorylated IRS-1 and p85 were altered by oxidative stress induced by an inhibitor of glutathione synthesis [164]. Similar results were obtained in adipose tissue and 3T3-L1 adipocytes [164, 165]. Additional evidences revealed that, in L6 myotubes, oxidative stress prevents insulin-induced actin reorganization [166]. Consequently, the molecular traffic required for insulin action could be regulated in a redox-dependent manner.

In the context of insulin resistance, studies showed that several insulin effectors are nitrosylated, a mechanism thought to inhibit insulin signaling. Indeed, insulin-stimulated Akt 


\section{ACCEPTED MANUSCRIPT}

phosphorylation and activity were reduced in the skeletal muscle of diabetic $\mathrm{db} / \mathrm{db}$ mice, this was associated with a drastic increase of Akt S-nitrosylation [167]. In the skeletal muscle of high-fat-fed rats and ob/ob mice, Carvalho-Filho et al. found a reduction of insulin-stimulated IR, IRS-1 and Akt phosphorylations, which was associated with an increase of their Snitrosylations [168]. In ob/ob mice, these effects were prevented by the downregulation of iNOS [168], suggesting a role of this enzyme in oxidative stress-induced insulin resistance. Additional evidence indicated that IRS-1 S-nitrosylation promotes its degradation in skeletal muscle [168]. Moreover, S-nitrosylation of Akt reduced its activity in C2C12 myotubes [167]. Consequently, S-nitrosylation of insulin effectors appears as a mechanism able to regulate insulin signaling in muscle fibers. In adipocytes, other studies pointed out a potential role of lipid peroxidation, protein nitration and carbonylation in the development of insulin resistance [169-171]. The Figure 4 illustrates the proposed mechanisms of RONS-induced insulin resistance in skeletal muscle.

As described in this section, physical inactivity and oxidative stress contribute to insulin resistance. However, it is currently unknown whether oxidative stress mediates physical inactivity-induced insulin resistance.

\section{Oxidant molecules: Doctor Jekyll and Mister Hyde}

Although attractive, the hypothesis developed in this section has been challenged. Indeed, antioxidant supplementation such as vitamin $\mathrm{C}$ and $\mathrm{E}$ provided disappointing results in type 2 diabetic patients [172]. As a consequence, this therapeutic strategy is not recommended to improve insulin action [172]. These puzzling results could be related to the complex relation between oxidative stress and insulin signaling. Depending on dose and exposure time, oxidant molecules are able to either inhibit or promote insulin action. As described above, RONS disrupt insulin signaling. However, RONS are also second messengers facilitating the transduction of insulin signaling [8]. These two faces of oxidant molecules may partly explain the failure of therapies seeking to alleviate oxidative stress in type 2 diabetes. Moreover, in human, antioxidant supplementation prevented the beneficial effect of exercise on insulin sensitivity [173], thus suggesting that therapies combining exercise and antioxidant are counterproductive. Taken together, these results indicate that the current antioxidants are not useful to fight against insulin resistance. However, other antioxidant strategies may prevent insulin resistance. Indeed, redox homeostasis appears as a complex system involving multiple RONS and antioxidant defenses operating in different compartments within tissues and cells. Moreover, RONS regulate essential processes to cell functions. Thus, several questions 


\section{ACCEPTED MANUSCRIPT}

deserve to be asked when using antioxidant: Which RONS is targeted ? Which source is targeted ? In what proportion RONS concentration should be reduced ?

\section{CONCLUDING REMARKS}

In this review, we examined the role of oxidative stress on physical inactivity and immobilization-induced, respectively, skeletal muscle insulin resistance and atrophy. First, in the literature a major confusion exists between the terms physical inactivity and immobilization. Physical inactivity is frequently associated with experiments where subjects are immobilized. Thus, caution must be taken when interpreting results from these studies. For the sake of clarity, we chose to make a clear distinction between physical inactivity and immobilization. We pointed out that skeletal muscle atrophy due to immobilization is a RONS-dependent process. In this condition, antioxidants provided promising results in animals, they need to be tested in human. On the other hand, the involvement of oxidative stress in physical inactivity-induced insulin resistance has not been investigated. This lack of data is, we believe, related to the confusion between physical inactivity and immobilization.

\section{CONFLICT OF INTEREST}

The authors declare that no conflict of interest exists.

\section{ACKNOWLEDGMENTS}

This work was supported by the Grant MUSFER-8802, from the Brittany Region Council.

\section{REFERENCES}

[1] Bergouignan, A.; Rudwill, F.; Simon, C.; Blanc, S. Physical inactivity as the culprit of metabolic inflexibility: evidence from bed-rest studies. J Appl Physiol (1985) 111:1201-1210; 2011.

[2] Hamburg, N. M.; McMackin, C. J.; Huang, A. L.; Shenouda, S. M.; Widlansky, M. E.; Schulz, E., et al. Physical inactivity rapidly induces insulin resistance and microvascular dysfunction in healthy volunteers. Arterioscler Thromb Vasc Biol 27:2650-2656; 2007.

[3] Morey-Holton, E.; Globus, R. K.; Kaplansky, A.; Durnova, G. The hindlimb unloading rat model: literature overview, technique update and comparison with space flight data. Adv Space Biol Med 10:7-40; 2005.

[4] Pedersen, B. K. The diseasome of physical inactivity--and the role of myokines in muscle--fat cross talk. J Physiol 587:5559-5568; 2009.

[5] Laye, M. J.; Thyfault, J. P.; Stump, C. S.; Booth, F. W. Inactivity induces increases in abdominal fat. J Appl Physiol (1985) 102:1341-1347; 2007.

[6] Xu, J.; Hwang, J. C.; Lees, H. A.; Wohlgemuth, S. E.; Knutson, M. D.; Judge, A. R., et al. Long-term perturbation of muscle iron homeostasis following hindlimb suspension in old rats is associated with high levels of oxidative stress and impaired recovery from atrophy. Exp Gerontol 47:100-108; 2012. 


\section{ACCEPTED MANUSCRIPT}

[7] Hokama, J. Y.; Streeper, R. S.; Henriksen, E. J. Voluntary exercise training enhances glucose transport in muscle stimulated by insulin-like growth factor I. J Appl Physiol (1985) 82:508-512; 1997.

[8] Bashan, N.; Kovsan, J.; Kachko, I.; Ovadia, H.; Rudich, A. Positive and negative regulation of insulin signaling by reactive oxygen and nitrogen species. Physiol Rev 89:27-71; 2009.

[9] Powers, S. K.; Smuder, A. J.; Criswell, D. S. Mechanistic links between oxidative stress and disuse muscle atrophy. Antioxid Redox Signal 15:2519-2528; 2011.

[10] Tremblay, M. S.; LeBlanc, A. G.; Kho, M. E.; Saunders, T. J.; Larouche, R.; Colley, R. C., et al. Systematic review of sedentary behaviour and health indicators in school-aged children and youth. Int J Behav Nutr Phys Act 8:98; 2011.

[11] WHO Global recommendations on physical activity for health. Geneva: World Health Organization; 2010.

[12] Hallal, P. C.; Andersen, L. B.; Bull, F. C.; Guthold, R.; Haskell, W.; Ekelund, U. Global physical activity levels: surveillance progress, pitfalls, and prospects. Lancet 380:247257; 2012.

[13] Mattson, M. P. Evolutionary aspects of human exercise--born to run purposefully. Ageing Res Rev 11:347-352; 2012.

[14] Hartley, P. H.; Llewellyn, G. F. Longevity of Oarsmen. Br Med J 1:657-662; 1939.

[15] Morris, J. N.; Heady, J. A. Mortality in relation to the physical activity of work: a preliminary note on experience in middle age. Br J Ind Med 10:245-254; 1953.

[16] Lee, I. M.; Shiroma, E. J.; Lobelo, F.; Puska, P.; Blair, S. N.; Katzmarzyk, P. T. Effect of physical inactivity on major non-communicable diseases worldwide: an analysis of burden of disease and life expectancy. Lancet 380:219-229; 2012.

[17] Centers For Disease Control and Prevention. National diabetes statistics report: estimates of diabetes and its burden in the United States, 2014. Atlanta, GA: Department of Health and Human Services; 2014.

[18] Strunk, B. C.; Ginsburg, P. B.; Banker, M. I. The effect of population aging on future hospital demand. Health Aff (Millwood) 25:w141-149; 2006.

[19] Jennings, L. A.; Auerbach, A. D.; Maselli, J.; Pekow, P. S.; Lindenauer, P. K.; Lee, S. J. Missed opportunities for osteoporosis treatment in patients hospitalized for hip fracture. $J$ Am Geriatr Soc 58:650-657; 2010.

[20] Kleinpell, R. M.; Fletcher, K.; Jennings, B. M. Reducing Functional Decline in Hospitalized Elderly. In: Hughes, R. G., ed. Patient Safety and Quality: An Evidence-Based Handbook for Nurses. Rockville (MD); 2008.

[21] Seynnes, O. R.; Maganaris, C. N.; de Boer, M. D.; di Prampero, P. E.; Narici, M. V. Early structural adaptations to unloading in the human calf muscles. Acta Physiol (Oxf) 193:265-274; 2008.

[22] Deschenes, M. R.; Holdren, A. N.; McCoy, R. W. Adaptations to short-term muscle unloading in young and aged men. Med Sci Sports Exerc 40:856-863; 2008.

[23] Borina, E.; Pellegrino, M. A.; D'Antona, G.; Bottinelli, R. Myosin and actin content of human skeletal muscle fibers following 35 days bed rest. Scand J Med Sci Sports 20:65-73; 2010.

[24] Covinsky, K. E.; Palmer, R. M.; Fortinsky, R. H.; Counsell, S. R.; Stewart, A. L.; Kresevic, D., et al. Loss of independence in activities of daily living in older adults hospitalized with medical illnesses: increased vulnerability with age. $J$ Am Geriatr Soc 51:451-458; 2003.

[25] Mercante, O.; Gagliardi, C.; Spazzafumo, L.; Gaspari, A.; David, S.; Cingolani, D., et al. Loss of autonomy of hospitalized elderly patients: does hospitalization increase disability? Eur J Phys Rehabil Med 50:703-708; 2014. 


\section{ACCEPTED MANUSCRIPT}

[26] Lyman, S.; Koulouvaris, P.; Sherman, S.; Do, H.; Mandl, L. A.; Marx, R. G. Epidemiology of anterior cruciate ligament reconstruction: trends, readmissions, and subsequent knee surgery. J Bone Joint Surg Am 91:2321-2328; 2009.

[27] Powers, S. K.; Jackson, M. J. Exercise-induced oxidative stress: cellular mechanisms and impact on muscle force production. Physiol Rev 88:1243-1276; 2008.

[28] Murphy, M. P. How mitochondria produce reactive oxygen species. Biochem J 417:1$13 ; 2009$.

[29] Barbieri, E.; Sestili, P. Reactive oxygen species in skeletal muscle signaling. J Signal Transduct 2012:982794; 2012.

[30] Csordas, G.; Hajnoczky, G. SR/ER-mitochondrial local communication: calcium and ROS. Biochim Biophys Acta 1787:1352-1362; 2009.

[31] Kleniewska, P.; Piechota, A.; Skibska, B.; Goraca, A. The NADPH oxidase family and its inhibitors. Arch Immunol Ther Exp (Warsz) 60:277-294; 2012.

[32] Cheng, G.; Cao, Z.; Xu, X.; van Meir, E. G.; Lambeth, J. D. Homologs of gp91phox: cloning and tissue expression of Nox3, Nox4, and Nox5. Gene 269:131-140; 2001.

[33] Nisimoto, Y.; Jackson, H. M.; Ogawa, H.; Kawahara, T.; Lambeth, J. D. Constitutive NADPH-dependent electron transferase activity of the Nox4 dehydrogenase domain. Biochemistry 49:2433-2442; 2010.

[34] Zuo, L.; Christofi, F. L.; Wright, V. P.; Bao, S.; Clanton, T. L. Lipoxygenasedependent superoxide release in skeletal muscle. J Appl Physiol (1985) 97:661-668; 2004.

[35] Gong, M. C.; Arbogast, S.; Guo, Z.; Mathenia, J.; Su, W.; Reid, M. B. Calciumindependent phospholipase A2 modulates cytosolic oxidant activity and contractile function in murine skeletal muscle cells. J Appl Physiol (1985) 100:399-405; 2006.

[36] Gomez-Cabrera, M. C.; Borras, C.; Pallardo, F. V.; Sastre, J.; Ji, L. L.; Vina, J. Decreasing xanthine oxidase-mediated oxidative stress prevents useful cellular adaptations to exercise in rats. $J$ Physiol 567:113-120; 2005.

[37] Hellsten, Y.; Frandsen, U.; Orthenblad, N.; Sjodin, B.; Richter, E. A. Xanthine oxidase in human skeletal muscle following eccentric exercise: a role in inflammation. J Physiol 498 ( Pt 1):239-248; 1997.

[38] Hwang, C.; Sinskey, A. J.; Lodish, H. F. Oxidized redox state of glutathione in the endoplasmic reticulum. Science 257:1496-1502; 1992.

[39] Zhang, K.; Kaufman, R. J. From endoplasmic-reticulum stress to the inflammatory response. Nature 454:455-462; 2008.

[40] Tu, B. P.; Weissman, J. S. Oxidative protein folding in eukaryotes: mechanisms and consequences. J Cell Biol 164:341-346; 2004.

[41] Tengan, C. H.; Rodrigues, G. S.; Godinho, R. O. Nitric oxide in skeletal muscle: role on mitochondrial biogenesis and function. Int J Mol Sci 13:17160-17184; 2012.

[42] Stamler, J. S.; Meissner, G. Physiology of nitric oxide in skeletal muscle. Physiol Rev 81:209-237; 2001.

[43] Reid, M. B. Role of nitric oxide in skeletal muscle: synthesis, distribution and functional importance. Acta Physiol Scand 162:401-409; 1998.

[44] Rains, J. L.; Jain, S. K. Oxidative stress, insulin signaling, and diabetes. Free Radic Biol Med 50:567-575; 2011.

[45] Powers, S. K.; Smuder, A. J.; Judge, A. R. Oxidative stress and disuse muscle atrophy: cause or consequence? Curr Opin Clin Nutr Metab Care 15:240-245; 2012.

[46] Stone, J. R.; Yang, S. Hydrogen peroxide: a signaling messenger. Antioxid Redox Signal 8:243-270; 2006.

[47] Kirkman, H. N.; Gaetani, G. F. Mammalian catalase: a venerable enzyme with new mysteries. Trends Biochem Sci 32:44-50; 2007. 


\section{ACCEPTED MANUSCRIPT}

[48] Schrader, M.; Fahimi, H. D. Peroxisomes and oxidative stress. Biochim Biophys Acta 1763:1755-1766; 2006.

[49] Powers, S. K.; Ji, L. L.; Kavazis, A. N.; Jackson, M. J. Reactive oxygen species: impact on skeletal muscle. Compr Physiol 1:941-969; 2011.

[50] Chakravarthi, S.; Jessop, C. E.; Bulleid, N. J. The role of glutathione in disulphide bond formation and endoplasmic-reticulum-generated oxidative stress. EMBO Rep 7:271-275; 2006.

[51] Pellegrino, M. A.; Desaphy, J. F.; Brocca, L.; Pierno, S.; Camerino, D. C.; Bottinelli, R. Redox homeostasis, oxidative stress and disuse muscle atrophy. J Physiol 589:2147-2160; 2011.

[52] Xu, X.; Chen, C. N.; Arriaga, E. A.; Thompson, L. V. Asymmetric superoxide release inside and outside the mitochondria in skeletal muscle under conditions of aging and disuse. $J$ Appl Physiol (1985) 109:1133-1139; 2010.

[53] Cannavino, J.; Brocca, L.; Sandri, M.; Bottinelli, R.; Pellegrino, M. A. PGC1-alpha over-expression prevents metabolic alterations and soleus muscle atrophy in hindlimb unloaded mice. J Physiol 592:4575-4589; 2014.

[54] Talbert, E. E.; Smuder, A. J.; Min, K.; Kwon, O. S.; Szeto, H. H.; Powers, S. K. Immobilization-induced activation of key proteolytic systems in skeletal muscles is prevented by a mitochondria-targeted antioxidant. J Appl Physiol (1985) 115:529-538; 2013.

[55] Min, K.; Smuder, A. J.; Kwon, O. S.; Kavazis, A. N.; Szeto, H. H.; Powers, S. K. Mitochondrial-targeted antioxidants protect skeletal muscle against immobilization-induced muscle atrophy. J Appl Physiol (1985) 111:1459-1466; 2011.

[56] Gram, M.; Vigelso, A.; Yokota, T.; Helge, J. W.; Dela, F.; Hey-Mogensen, M. Skeletal muscle mitochondrial $\mathrm{H} 2 \mathrm{O} 2$ emission increases with immobilization and decreases after aerobic training in young and older men. J Physiol 593:4011-4027; 2015.

[57] Derbre, F.; Ferrando, B.; Gomez-Cabrera, M. C.; Sanchis-Gomar, F.; Martinez-Bello, V. E.; Olaso-Gonzalez, G., et al. Inhibition of xanthine oxidase by allopurinol prevents skeletal muscle atrophy: role of p38 MAPKinase and E3 ubiquitin ligases. PLoS One 7:e46668; 2012.

[58] Kondo, H.; Miura, M.; Itokawa, Y. Oxidative stress in skeletal muscle atrophied by immobilization. Acta Physiol Scand 142:527-528; 1991.

[59] Andrianjafiniony, T.; Dupre-Aucouturier, S.; Letexier, D.; Couchoux, H.; Desplanches, D. Oxidative stress, apoptosis, and proteolysis in skeletal muscle repair after unloading. Am J Physiol Cell Physiol 299:C307-315; 2010.

[60] Dupre-Aucouturier, S.; Castells, J.; Freyssenet, D.; Desplanches, D. Trichostatin A, a histone deacetylase inhibitor, modulates unloaded-induced skeletal muscle atrophy. $J$ Appl Physiol (1985) 119:342-351; 2015.

[61] Servais, S.; Letexier, D.; Favier, R.; Duchamp, C.; Desplanches, D. Prevention of unloading-induced atrophy by vitamin E supplementation: links between oxidative stress and soleus muscle proteolysis? Free Radic Biol Med 42:627-635; 2007.

[62] Cannavino, J.; Brocca, L.; Sandri, M.; Grassi, B.; Bottinelli, R.; Pellegrino, M. A. The role of alterations in mitochondrial dynamics and PGC-1alpha over-expression in fast muscle atrophy following hindlimb unloading. J Physiol 593:1981-1995; 2015.

[63] Kondo, H.; Miura, M.; Itokawa, Y. Antioxidant enzyme systems in skeletal muscle atrophied by immobilization. Pflugers Arch 422:404-406; 1993.

[64] Selsby, J. T.; Dodd, S. L. Heat treatment reduces oxidative stress and protects muscle mass during immobilization. Am J Physiol Regul Integr Comp Physiol 289:R134-139; 2005.

[65] Kondo, H.; Nakagaki, I.; Sasaki, S.; Hori, S.; Itokawa, Y. Mechanism of oxidative stress in skeletal muscle atrophied by immobilization. Am J Physiol 265:E839-844; 1993. 


\section{ACCEPTED MANUSCRIPT}

[66] Dalla Libera, L.; Ravara, B.; Gobbo, V.; Tarricone, E.; Vitadello, M.; Biolo, G., et al. A transient antioxidant stress response accompanies the onset of disuse atrophy in human skeletal muscle. J Appl Physiol (1985) 107:549-557; 2009.

[67] Glover, E. I.; Yasuda, N.; Tarnopolsky, M. A.; Abadi, A.; Phillips, S. M. Little change in markers of protein breakdown and oxidative stress in humans in immobilization-induced skeletal muscle atrophy. Appl Physiol Nutr Me 35:125-133; 2010.

[68] Ota, N.; Soga, S.; Haramizu, S.; Yokoi, Y.; Hase, T.; Murase, T. Tea catechins prevent contractile dysfunction in unloaded murine soleus muscle: a pilot study. Nutrition 27:955959; 2011.

[69] Vitadello, M.; Germinario, E.; Ravara, B.; Libera, L. D.; Danieli-Betto, D.; Gorza, L. Curcumin counteracts loss of force and atrophy of hindlimb unloaded rat soleus by hampering neuronal nitric oxide synthase untethering from sarcolemma. J Physiol 592:2637-2652; 2014.

[70] Vitadello, M.; Gherardini, J.; Gorza, L. The stress protein/chaperone Grp94 counteracts muscle disuse atrophy by stabilizing subsarcolemmal neuronal nitric oxide synthase. Antioxid Redox Signal 20:2479-2496; 2014.

[71] Lawler, J. M.; Kunst, M.; Hord, J. M.; Lee, Y.; Joshi, K.; Botchlett, R. E., et al. EUK134 ameliorates nNOSmu translocation and skeletal muscle fiber atrophy during short-term mechanical unloading. Am J Physiol Regul Integr Comp Physiol 306:R470-482; 2014.

[72] Curtis, J. M.; Hahn, W. S.; Long, E. K.; Burrill, J. S.; Arriaga, E. A.; Bernlohr, D. A. Protein carbonylation and metabolic control systems. Trends Endocrinol Metab 23:399-406; 2012.

[73] Jones, D. P. Radical-free biology of oxidative stress. Am J Physiol Cell Physiol 295:C849-868; 2008.

[74] Phillips, S. M.; McGlory, C. CrossTalk proposal: The dominant mechanism causing disuse muscle atrophy is decreased protein synthesis. J Physiol 592:5341-5343; 2014.

[75] You, J. S.; Anderson, G. B.; Dooley, M. S.; Hornberger, T. A. The role of mTOR signaling in the regulation of protein synthesis and muscle mass during immobilization in mice. Dis Model Mech 8:1059-1069; 2015.

[76] Kelleher, A. R.; Kimball, S. R.; Dennis, M. D.; Schilder, R. J.; Jefferson, L. S. The mTORC1 signaling repressors REDD1/2 are rapidly induced and activation of p70S6K1 by leucine is defective in skeletal muscle of an immobilized rat hindlimb. Am J Physiol Endocrinol Metab 304:E229-236; 2013.

[77] Ferrando, A. A.; Tipton, K. D.; Bamman, M. M.; Wolfe, R. R. Resistance exercise maintains skeletal muscle protein synthesis during bed rest. J Appl Physiol (1985) 82:807810; 1997.

[78] Paddon-Jones, D.; Sheffield-Moore, M.; Cree, M. G.; Hewlings, S. J.; Aarsland, A.; Wolfe, R. R., et al. Atrophy and impaired muscle protein synthesis during prolonged inactivity and stress. J Clin Endocrinol Metab 91:4836-4841; 2006.

[79] Sandri, M. Signaling in muscle atrophy and hypertrophy. Physiology (Bethesda) 23:160-170; 2008.

[80] Drummond, M. J.; Dickinson, J. M.; Fry, C. S.; Walker, D. K.; Gundermann, D. M.; Reidy, P. T., et al. Bed rest impairs skeletal muscle amino acid transporter expression, mTORC1 signaling, and protein synthesis in response to essential amino acids in older adults. Am J Physiol Endocrinol Metab 302:E1113-1122; 2012.

[81] Dupont, E.; Cieniewski-Bernard, C.; Bastide, B.; Stevens, L. Electrostimulation during hindlimb unloading modulates PI3K-AKT downstream targets without preventing soleus atrophy and restores slow phenotype through ERK. Am J Physiol Regul Integr Comp Physiol 300:R408-417; 2011. 


\section{ACCEPTED MANUSCRIPT}

[82] Biolo, G.; Ciocchi, B.; Lebenstedt, M.; Barazzoni, R.; Zanetti, M.; Platen, P., et al. Short-term bed rest impairs amino acid-induced protein anabolism in humans. J Physiol 558:381-388; 2004.

[83] Allen, D. L.; Roy, R. R.; Edgerton, V. R. Myonuclear domains in muscle adaptation and disease. Muscle Nerve 22:1350-1360; 1999.

[84] Pavlath, G. K.; Rich, K.; Webster, S. G.; Blau, H. M. Localization of muscle gene products in nuclear domains. Nature 337:570-573; 1989.

[85] Allen, D. L.; Linderman, J. K.; Roy, R. R.; Bigbee, A. J.; Grindeland, R. E.; Mukku, $\mathrm{V}$., et al. Apoptosis: a mechanism contributing to remodeling of skeletal muscle in response to hindlimb unweighting. Am J Physiol 273:C579-587; 1997.

[86] Dupont-Versteegden, E. E.; Strotman, B. A.; Gurley, C. M.; Gaddy, D.; Knox, M.; Fluckey, J. D., et al. Nuclear translocation of EndoG at the initiation of disuse muscle atrophy and apoptosis is specific to myonuclei. Am J Physiol Regul Integr Comp Physiol 291:R17301740; 2006.

[87] Siu, P. M.; Pistilli, E. E.; Butler, D. C.; Alway, S. E. Aging influences cellular and molecular responses of apoptosis to skeletal muscle unloading. Am J Physiol Cell Physiol 288:C338-349; 2005.

[88] Leeuwenburgh, C.; Gurley, C. M.; Strotman, B. A.; Dupont-Versteegden, E. E. Agerelated differences in apoptosis with disuse atrophy in soleus muscle. Am J Physiol Regul Integr Comp Physiol 288:R1288-1296; 2005.

[89] Talbert, E. E.; Smuder, A. J.; Min, K.; Kwon, O. S.; Powers, S. K. Calpain and caspase-3 play required roles in immobilization-induced limb muscle atrophy. J Appl Physiol (1985) 114:1482-1489; 2013.

[90] Siu, P. M.; Pistilli, E. E.; Alway, S. E. Apoptotic responses to hindlimb suspension in gastrocnemius muscles from young adult and aged rats. Am J Physiol Regul Integr Comp Physiol 289:R1015-1026; 2005.

[91] Bruusgaard, J. C.; Gundersen, K. In vivo time-lapse microscopy reveals no loss of murine myonuclei during weeks of muscle atrophy. J Clin Invest 118:1450-1457; 2008.

[92] Munoz, K. A.; Satarug, S.; Tischler, M. E. Time course of the response of myofibrillar and sarcoplasmic protein metabolism to unweighting of the soleus muscle. Metabolism 42:1006-1012; 1993.

[93] Huang, J.; Forsberg, N. E. Role of calpain in skeletal-muscle protein degradation. Proc Natl Acad Sci U S A 95:12100-12105; 1998.

[94] Du, J.; Wang, X.; Miereles, C.; Bailey, J. L.; Debigare, R.; Zheng, B., et al. Activation of caspase-3 is an initial step triggering accelerated muscle proteolysis in catabolic conditions. J Clin Invest 113:115-123; 2004.

[95] Vermaelen, M.; Sirvent, P.; Raynaud, F.; Astier, C.; Mercier, J.; Lacampagne, A., et al. Differential localization of autolyzed calpains 1 and 2 in slow and fast skeletal muscles in the early phase of atrophy. Am J Physiol Cell Physiol 292:C1723-1731; 2007.

[96] Shenkman, B. S.; Belova, S. P.; Lomonosova, Y. N.; Kostrominova, T. Y.; Nemirovskaya, T. L. Calpain-dependent regulation of the skeletal muscle atrophy following unloading. Arch Biochem Biophys 584:36-41; 2015.

[97] Ogawa, T.; Furochi, H.; Mameoka, M.; Hirasaka, K.; Onishi, Y.; Suzue, N., et al. Ubiquitin ligase gene expression in healthy volunteers with 20-day bedrest. Muscle Nerve 34:463-469; 2006.

[98] Krawiec, B. J.; Frost, R. A.; Vary, T. C.; Jefferson, L. S.; Lang, C. H. Hindlimb casting decreases muscle mass in part by proteasome-dependent proteolysis but independent of protein synthesis. Am J Physiol Endocrinol Metab 289:E969-980; 2005. 


\section{ACCEPTED MANUSCRIPT}

[99] Tanner, R. E.; Brunker, L. B.; Agergaard, J.; Barrows, K. M.; Briggs, R. A.; Kwon, O. S., et al. Age-related differences in lean mass, protein synthesis and skeletal muscle markers of proteolysis after bed rest and exercise rehabilitation. J Physiol 593:4259-4273; 2015.

[100] Foletta, V. C.; White, L. J.; Larsen, A. E.; Leger, B.; Russell, A. P. The role and regulation of MAFbx/atrogin-1 and MuRF1 in skeletal muscle atrophy. Pflugers Arch 461:325-335; 2011.

[101] Wu, C. L.; Cornwell, E. W.; Jackman, R. W.; Kandarian, S. C. NF-kappaB but not FoxO sites in the MuRF1 promoter are required for transcriptional activation in disuse muscle atrophy. Am J Physiol Cell Physiol 306:C762-767; 2014.

[102] Hunter, R. B.; Stevenson, E.; Koncarevic, A.; Mitchell-Felton, H.; Essig, D. A.; Kandarian, S. C. Activation of an alternative NF-kappaB pathway in skeletal muscle during disuse atrophy. FASEB J 16:529-538; 2002.

[103] Judge, A. R.; Koncarevic, A.; Hunter, R. B.; Liou, H. C.; Jackman, R. W.; Kandarian, S. C. Role for IkappaBalpha, but not c-Rel, in skeletal muscle atrophy. Am J Physiol Cell Physiol 292:C372-382; 2007.

[104] Hunter, R. B.; Kandarian, S. C. Disruption of either the Nfkb1 or the Bcl3 gene inhibits skeletal muscle atrophy. J Clin Invest 114:1504-1511; 2004.

[105] Sandri, M.; Sandri, C.; Gilbert, A.; Skurk, C.; Calabria, E.; Picard, A., et al. Foxo transcription factors induce the atrophy-related ubiquitin ligase atrogin-1 and cause skeletal muscle atrophy. Cell 117:399-412; 2004.

[106] Sandri, M.; Lin, J.; Handschin, C.; Yang, W.; Arany, Z. P.; Lecker, S. H., et al. PGC1alpha protects skeletal muscle from atrophy by suppressing FoxO3 action and atrophyspecific gene transcription. Proc Natl Acad Sci U S A 103:16260-16265; 2006.

[107] Senf, S. M.; Dodd, S. L.; Judge, A. R. FOXO signaling is required for disuse muscle atrophy and is directly regulated by Hsp70. Am J Physiol Cell Physiol 298:C38-45; 2010.

[108] Waddell, D. S.; Baehr, L. M.; van den Brandt, J.; Johnsen, S. A.; Reichardt, H. M.; Furlow, J. D., et al. The glucocorticoid receptor and FOXO1 synergistically activate the skeletal muscle atrophy-associated MuRF1 gene. Am J Physiol Endocrinol Metab 295:E785797; 2008.

[109] Pidcoke, H. F.; Baer, L. A.; Wu, X.; Wolf, S. E.; Aden, J. K.; Wade, C. E. Insulin effects on glucose tolerance, hypermetabolic response, and circadian-metabolic protein expression in a rat burn and disuse model. Am J Physiol Regul Integr Comp Physiol 307:R1R10; 2014.

[110] Sakuma, K.; Watanabe, K.; Hotta, N.; Koike, T.; Ishida, K.; Katayama, K., et al. The adaptive responses in several mediators linked with hypertrophy and atrophy of skeletal muscle after lower limb unloading in humans. Acta Physiol (Oxf) 197:151-159; 2009.

[111] Gustafsson, T.; Osterlund, T.; Flanagan, J. N.; von Walden, F.; Trappe, T. A.; Linnehan, R. M., et al. Effects of 3 days unloading on molecular regulators of muscle size in humans. J Appl Physiol (1985) 109:721-727; 2010.

[112] Sandri, M. Autophagy in health and disease. 3. Involvement of autophagy in muscle atrophy. Am J Physiol Cell Physiol 298:C1291-1297; 2010.

[113] Madaro, L.; Marrocco, V.; Carnio, S.; Sandri, M.; Bouche, M. Intracellular signaling in ER stress-induced autophagy in skeletal muscle cells. FASEB J 27:1990-2000; 2013.

[114] Brocca, L.; Cannavino, J.; Coletto, L.; Biolo, G.; Sandri, M.; Bottinelli, R., et al. The time course of the adaptations of human muscle proteome to bed rest and the underlying mechanisms. J Physiol 590:5211-5230; 2012.

[115] Zhang, G.; Jin, B.; Li, Y. P. C/EBPbeta mediates tumour-induced ubiquitin ligase atrogin1/MAFbx upregulation and muscle wasting. EMBO J 30:4323-4335; 2011.

[116] Siu, P. M.; Wang, Y.; Alway, S. E. Apoptotic signaling induced by H2O2-mediated oxidative stress in differentiated C2C12 myotubes. Life Sci 84:468-481; 2009. 


\section{ACCEPTED MANUSCRIPT}

[117] McClung, J. M.; Judge, A. R.; Talbert, E. E.; Powers, S. K. Calpain-1 is required for hydrogen peroxide-induced myotube atrophy. Am J Physiol Cell Physiol 296:C363-371; 2009.

[118] Li, Y. P.; Chen, Y.; Li, A. S.; Reid, M. B. Hydrogen peroxide stimulates ubiquitinconjugating activity and expression of genes for specific E2 and E3 proteins in skeletal muscle myotubes. Am J Physiol Cell Physiol 285:C806-812; 2003.

[119] Li, Y. P.; Chen, Y.; John, J.; Moylan, J.; Jin, B.; Mann, D. L., et al. TNF-alpha acts via p38 MAPK to stimulate expression of the ubiquitin ligase atrogin1/MAFbx in skeletal muscle. FASEB J 19:362-370; 2005.

[120] Gilliam, L. A.; Moylan, J. S.; Patterson, E. W.; Smith, J. D.; Wilson, A. S.; Rabbani, Z., et al. Doxorubicin acts via mitochondrial ROS to stimulate catabolism in C2C12 myotubes. Am J Physiol Cell Physiol 302:C195-202; 2012.

[121] Dodd, S. L.; Gagnon, B. J.; Senf, S. M.; Hain, B. A.; Judge, A. R. Ros-mediated activation of NF-kappaB and Foxo during muscle disuse. Muscle Nerve 41:110-113; 2010.

[122] Matuszczak, Y.; Arbogast, S.; Reid, M. B. Allopurinol mitigates muscle contractile dysfunction caused by hindlimb unloading in mice. Aviat Space Environ Med 75:581-588; 2004.

[123] Appell, H. J.; Duarte, J. A.; Soares, J. M. Supplementation of vitamin E may attenuate skeletal muscle immobilization atrophy. Int J Sports Med 18:157-160; 1997.

[124] Momken, I.; Stevens, L.; Bergouignan, A.; Desplanches, D.; Rudwill, F.; Chery, I., et al. Resveratrol prevents the wasting disorders of mechanical unloading by acting as a physical exercise mimetic in the rat. FASEB J 25:3646-3660; 2011.

[125] Farid, M.; Reid, M. B.; Li, Y. P.; Gerken, E.; Durham, W. J. Effects of dietary curcumin or N-acetylcysteine on NF-kappaB activity and contractile performance in ambulatory and unloaded murine soleus. Nutr Metab (Lond) 2:20; 2005.

[126] DeFronzo, R. A.; Jacot, E.; Jequier, E.; Maeder, E.; Wahren, J.; Felber, J. P. The effect of insulin on the disposal of intravenous glucose. Results from indirect calorimetry and hepatic and femoral venous catheterization. Diabetes 30:1000-1007; 1981.

[127] Chang, L.; Chiang, S. H.; Saltiel, A. R. Insulin signaling and the regulation of glucose transport. Mol Med 10:65-71; 2004.

[128] White, M. F.; Kahn, C. R. The insulin signaling system. J Biol Chem 269:1-4; 1994.

[129] White, M. F. Insulin signaling in health and disease. Science 302:1710-1711; 2003.

[130] Hers, I.; Vincent, E. E.; Tavare, J. M. Akt signalling in health and disease. Cell Signal 23:1515-1527; 2011.

[131] Sakamoto, K.; Holman, G. D. Emerging role for AS160/TBC1D4 and TBC1D1 in the regulation of GLUT4 traffic. Am J Physiol Endocrinol Metab 295:E29-37; 2008.

[132] Stockli, J.; Fazakerley, D. J.; James, D. E. GLUT4 exocytosis. J Cell Sci 124:41474159; 2011.

[133] Chiu, T. T.; Jensen, T. E.; Sylow, L.; Richter, E. A.; Klip, A. Rac1 signalling towards GLUT4/glucose uptake in skeletal muscle. Cell Signal 23:1546-1554; 2011.

[134] Wallace, T. M.; Levy, J. C.; Matthews, D. R. Use and abuse of HOMA modeling. Diabetes Care 27:1487-1495; 2004.

[135] Matsuda, M.; DeFronzo, R. A. Insulin sensitivity indices obtained from oral glucose tolerance testing: comparison with the euglycemic insulin clamp. Diabetes Care 22:1462$1470 ; 1999$.

[136] Balkau, B.; Mhamdi, L.; Oppert, J. M.; Nolan, J.; Golay, A.; Porcellati, F., et al. Physical activity and insulin sensitivity: the RISC study. Diabetes 57:2613-2618; 2008.

[137] Kavouras, S. A.; Panagiotakos, D. B.; Pitsavos, C.; Chrysohoou, C.; Anastasiou, C. A.; Lentzas, Y., et al. Physical activity, obesity status, and glycemic control: The ATTICA study. Med Sci Sports Exerc 39:606-611; 2007. 


\section{ACCEPTED MANUSCRIPT}

[138] Olsen, R. H.; Krogh-Madsen, R.; Thomsen, C.; Booth, F. W.; Pedersen, B. K. Metabolic responses to reduced daily steps in healthy nonexercising men. JAMA 299:12611263; 2008.

[139] Reynolds, L. J.; Credeur, D. P.; Holwerda, S. W.; Leidy, H. J.; Fadel, P. J.; Thyfault, J. P. Acute inactivity impairs glycemic control but not blood flow to glucose ingestion. Med Sci Sports Exerc 47:1087-1094; 2015.

[140] Holwerda, S. W.; Reynolds, L. J.; Restaino, R. M.; Credeur, D. P.; Leidy, H. J.; Thyfault, J. P., et al. The influence of reduced insulin sensitivity via short-term reductions in physical activity on cardiac baroreflex sensitivity during acute hyperglycemia. J Appl Physiol (1985):jap 00584 02015; 2015.

[141] Krogh-Madsen, R.; Thyfault, J. P.; Broholm, C.; Mortensen, O. H.; Olsen, R. H.; Mounier, R., et al. A 2-wk reduction of ambulatory activity attenuates peripheral insulin sensitivity. J Appl Physiol (1985) 108:1034-1040; 2010.

[142] Kump, D. S.; Booth, F. W. Alterations in insulin receptor signalling in the rat epitrochlearis muscle upon cessation of voluntary exercise. J Physiol 562:829-838; 2005.

[143] Gratas-Delamarche, A.; Derbre, F.; Vincent, S.; Cillard, J. Physical inactivity, insulin resistance, and the oxidative-inflammatory loop. Free Radic Res 48:93-108; 2014.

[144] de Luca, C.; Olefsky, J. M. Inflammation and insulin resistance. FEBS Lett 582:97$105 ; 2008$.

[145] Shi, H.; Kokoeva, M. V.; Inouye, K.; Tzameli, I.; Yin, H.; Flier, J. S. TLR4 links innate immunity and fatty acid-induced insulin resistance. J Clin Invest 116:3015-3025; 2006.

[146] Chavez, J. A.; Knotts, T. A.; Wang, L. P.; Li, G.; Dobrowsky, R. T.; Florant, G. L., et al. A role for ceramide, but not diacylglycerol, in the antagonism of insulin signal transduction by saturated fatty acids. J Biol Chem 278:10297-10303; 2003.

[147] Martins, A. R.; Nachbar, R. T.; Gorjao, R.; Vinolo, M. A.; Festuccia, W. T.; Lambertucci, R. H., et al. Mechanisms underlying skeletal muscle insulin resistance induced by fatty acids: importance of the mitochondrial function. Lipids Health Dis 11:30; 2012.

[148] Eriksson, J. W. Metabolic stress in insulin's target cells leads to ROS accumulation - a hypothetical common pathway causing insulin resistance. FEBS Lett 581:3734-3742; 2007.

[149] Evans, J. L.; Goldfine, I. D.; Maddux, B. A.; Grodsky, G. M. Oxidative stress and stress-activated signaling pathways: a unifying hypothesis of type 2 diabetes. Endocr Rev 23:599-622; 2002.

[150] Hoehn, K. L.; Salmon, A. B.; Hohnen-Behrens, C.; Turner, N.; Hoy, A. J.; Maghzal, G. J., et al. Insulin resistance is a cellular antioxidant defense mechanism. Proc Natl Acad Sci U S A 106:17787-17792; 2009.

[151] Houstis, N.; Rosen, E. D.; Lander, E. S. Reactive oxygen species have a causal role in multiple forms of insulin resistance. Nature 440:944-948; 2006.

[152] Bloch-Damti, A.; Bashan, N. Proposed mechanisms for the induction of insulin resistance by oxidative stress. Antioxid Redox Signal 7:1553-1567; 2005.

[153] Gao, Z.; Hwang, D.; Bataille, F.; Lefevre, M.; York, D.; Quon, M. J., et al. Serine phosphorylation of insulin receptor substrate 1 by inhibitor kappa B kinase complex. $J$ Biol Chem 277:48115-48121; 2002.

[154] Rohl, M.; Pasparakis, M.; Baudler, S.; Baumgartl, J.; Gautam, D.; Huth, M., et al. Conditional disruption of IkappaB kinase 2 fails to prevent obesity-induced insulin resistance. J Clin Invest 113:474-481; 2004.

[155] Pal, M.; Wunderlich, C. M.; Spohn, G.; Bronneke, H. S.; Schmidt-Supprian, M.; Wunderlich, F. T. Alteration of JNK-1 signaling in skeletal muscle fails to affect glucose homeostasis and obesity-associated insulin resistance in mice. PLoS One 8:e54247; 2013. 


\section{ACCEPTED MANUSCRIPT}

[156] Cai, D.; Frantz, J. D.; Tawa, N. E., Jr.; Melendez, P. A.; Oh, B. C.; Lidov, H. G., et al. IKKbeta/NF-kappaB activation causes severe muscle wasting in mice. Cell 119:285-298; 2004.

[157] Hoehn, K. L.; Hohnen-Behrens, C.; Cederberg, A.; Wu, L. E.; Turner, N.; Yuasa, T., et al. IRS1-independent defects define major nodes of insulin resistance. Cell Metab 7:421433; 2008.

[158] Copps, K. D.; Hancer, N. J.; Opare-Ado, L.; Qiu, W.; Walsh, C.; White, M. F. Irs1 serine 307 promotes insulin sensitivity in mice. Cell Metab 11:84-92; 2010.

[159] Rudich, A.; Tirosh, A.; Potashnik, R.; Hemi, R.; Kanety, H.; Bashan, N. Prolonged oxidative stress impairs insulin-induced GLUT4 translocation in 3T3-L1 adipocytes. Diabetes 47:1562-1569; 1998.

[160] Pessler, D.; Rudich, A.; Bashan, N. Oxidative stress impairs nuclear proteins binding to the insulin responsive element in the GLUT4 promoter. Diabetologia 44:2156-2164; 2001.

[161] Kampmann, U.; Christensen, B.; Nielsen, T. S.; Pedersen, S. B.; Orskov, L.; Lund, S., et al. GLUT4 and UBC9 protein expression is reduced in muscle from type 2 diabetic patients with severe insulin resistance. PLoS One 6:e27854; 2011.

[162] Ingram, K. H.; Hill, H.; Moellering, D. R.; Hill, B. G.; Lara-Castro, C.; Newcomer, B., et al. Skeletal muscle lipid peroxidation and insulin resistance in humans. J Clin Endocrinol Metab 97:E1182-1186; 2012.

[163] Holloszy, J. O. Regulation by exercise of skeletal muscle content of mitochondria and GLUT4. J Physiol Pharmacol 59 Suppl 7:5-18; 2008.

[164] Ogihara, T.; Asano, T.; Katagiri, H.; Sakoda, H.; Anai, M.; Shojima, N., et al. Oxidative stress induces insulin resistance by activating the nuclear factor-kappa B pathway and disrupting normal subcellular distribution of phosphatidylinositol 3-kinase. Diabetologia 47:794-805; 2004.

[165] Tirosh, A.; Potashnik, R.; Bashan, N.; Rudich, A. Oxidative stress disrupts insulininduced cellular redistribution of insulin receptor substrate-1 and phosphatidylinositol 3kinase in 3T3-L1 adipocytes. A putative cellular mechanism for impaired protein kinase B activation and GLUT4 translocation. J Biol Chem 274:10595-10602; 1999.

[166] JeBailey, L.; Wanono, O.; Niu, W.; Roessler, J.; Rudich, A.; Klip, A. Ceramide- and oxidant-induced insulin resistance involve loss of insulin-dependent Rac-activation and actin remodeling in muscle cells. Diabetes 56:394-403; 2007.

[167] Yasukawa, T.; Tokunaga, E.; Ota, H.; Sugita, H.; Martyn, J. A.; Kaneki, M. Snitrosylation-dependent inactivation of Akt/protein kinase B in insulin resistance. J Biol Chem 280:7511-7518; 2005.

[168] Carvalho-Filho, M. A.; Ueno, M.; Hirabara, S. M.; Seabra, A. B.; Carvalheira, J. B.; de Oliveira, M. G., et al. S-nitrosation of the insulin receptor, insulin receptor substrate 1 , and protein kinase B/Akt: a novel mechanism of insulin resistance. Diabetes 54:959-967; 2005.

[169] Grimsrud, P. A.; Picklo, M. J., Sr.; Griffin, T. J.; Bernlohr, D. A. Carbonylation of adipose proteins in obesity and insulin resistance: identification of adipocyte fatty acidbinding protein as a cellular target of 4-hydroxynonenal. Mol Cell Proteomics 6:624-637; 2007.

[170] Demozay, D.; Mas, J. C.; Rocchi, S.; Van Obberghen, E. FALDH reverses the deleterious action of oxidative stress induced by lipid peroxidation product 4-hydroxynonenal on insulin signaling in 3T3-L1 adipocytes. Diabetes 57:1216-1226; 2008.

[171] Nomiyama, T.; Igarashi, Y.; Taka, H.; Mineki, R.; Uchida, T.; Ogihara, T., et al. Reduction of insulin-stimulated glucose uptake by peroxynitrite is concurrent with tyrosine nitration of insulin receptor substrate-1. Biochem Biophys Res Commun 320:639-647; 2004.

[172] Ceriello, A.; Testa, R. Antioxidant anti-inflammatory treatment in type 2 diabetes. Diabetes Care 32 Suppl 2:S232-236; 2009. 


\section{ACCEPTED MANUSCRIPT}

[173] Ristow, M.; Zarse, K.; Oberbach, A.; Kloting, N.; Birringer, M.; Kiehntopf, M., et al. Antioxidants prevent health-promoting effects of physical exercise in humans. Proc Natl Acad Sci U S A 106:8665-8670; 2009.

Figure 1. Human and rodent models used to study immobilization and physical inactivity. WHO: World Health Organization.

Figure 2. Mechanism of RONS-induced skeletal muscle atrophy in immobilization UPS: ubiquitin proteasome system; RONS: reactive oxygen and nitrogen species.

Figure 3. Regulation of glucose uptake by insulin. See details in the text. IR: insulin receptor; IRS: insulin receptor substrate; GLUT4: glucose transporter 4; mTORC2: mammalian target of rapamycin complex 2; PDK1: phosphoinositide-dependent kinase-1; $\mathrm{PIP}_{2}$ : phosphatidylinositol 4,5-diphosphate; $\mathrm{PIP}_{3}$ : phosphatidylinositol 3,4,5-trisphosphate; PI3K: phosphatidyl inositol 3-kinase.

Figure 4. Proposed mechanisms of RONS-induced insulin resistance in skeletal muscle. The effect of physical inactivity on skeletal muscle oxidative stress is currently unknown. RONS: reactive oxygen and nitrogen species.

\section{HIGHLIGHTS}

- The terms physical inactivity and immobilization are a source of confusion in the literature

- Immobilization alters redox homeostasis in skeletal muscle

- RONS play a key role in immobilization-induced skeletal muscle atrophy

- Lack of data regarding the effect of physical inactivity on skeletal muscle oxidative stress

- The role of RONS in physical inactivity-induced insulin resistance needs to be investigated 


\section{ACCEPTED MANUSCRIPT}

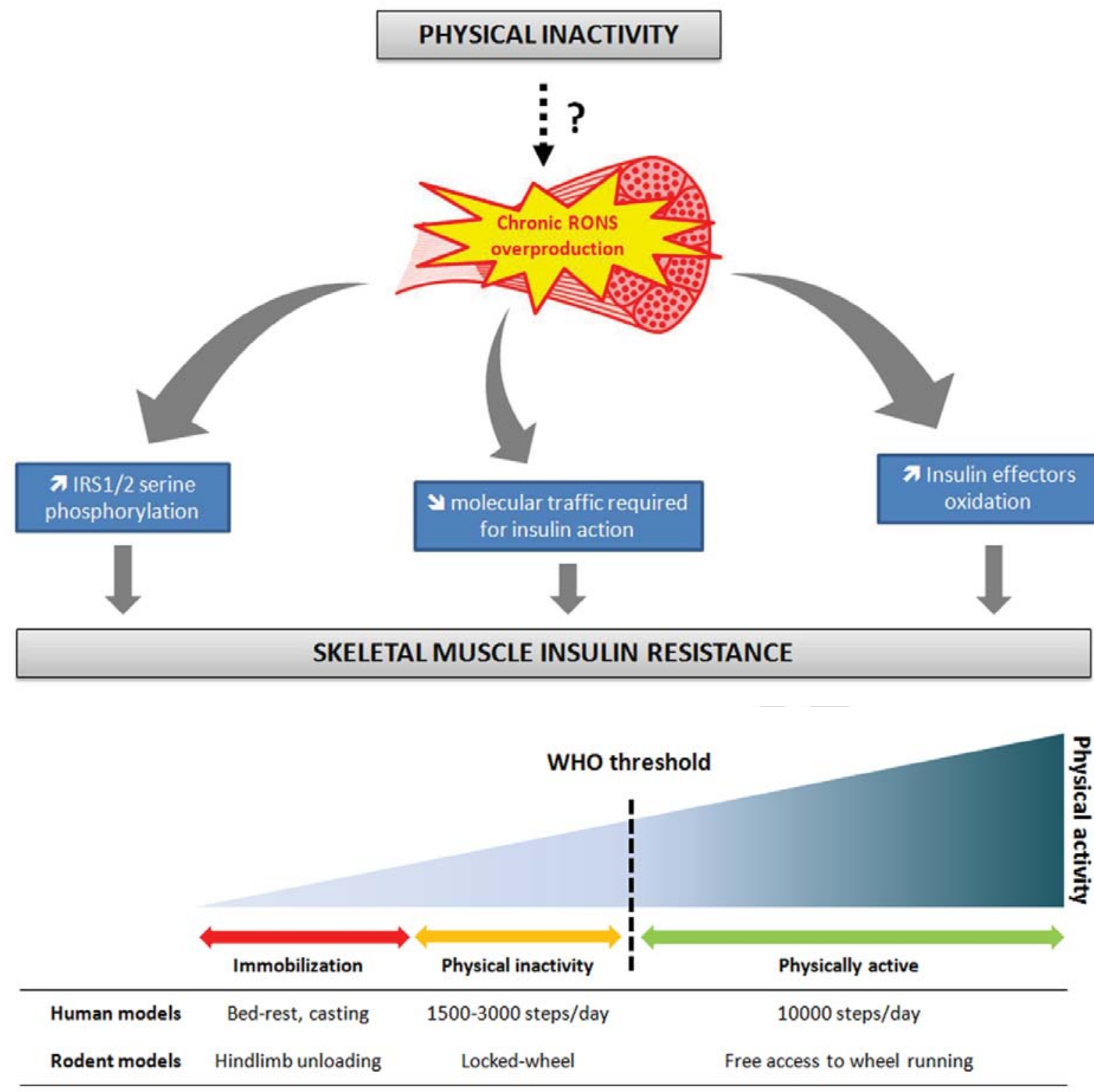




\section{ACCEPTED MANUSCRIPT}
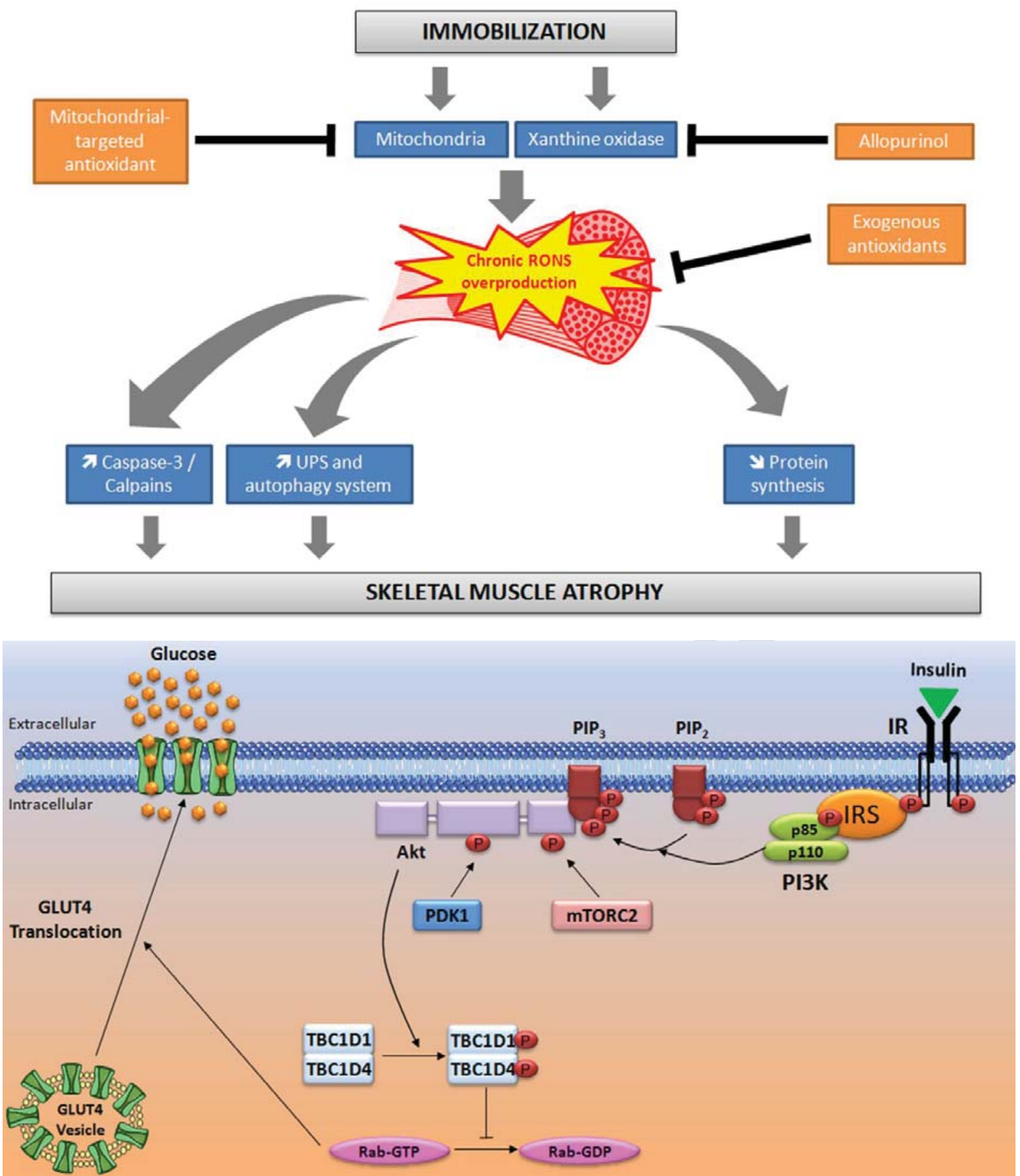